\title{
Fatal Hemorrhagic Gastrointestinal Angioectasia after Bone Marrow Transplantation for Dyskeratosis Congenita
}

\author{
Jin Imai ${ }^{1}$, Takayoshi Suzuki ${ }^{1}$, Marie Yoshikawa ${ }^{1}$, Makiko Dekiden ${ }^{1}$, Hirohiko Nakae ${ }^{1}$, \\ Fumio Nakahara ${ }^{1}$, Shingo Tsuda ${ }^{1}$, Hajime Mizukami ${ }^{1}$, Jun Koike ${ }^{1}$, Muneki Igarashi ${ }^{1}$, \\ Hiromasa Yabe $^{2}$ and Tetsuya Mine ${ }^{1}$
}

\begin{abstract}
Dyskeratosis congenita (DC) is a rare inherited disease in which the telomere complex cannot be maintained. Shortened telomeres can cause a number of clinical conditions. We herein report a case of unrelated bone marrow transplantation due to aplastic anemia associated with DC. The patient died of uncontrollable refractory intestinal bleeding. Three cases of DC with life-threatening hemorrhaging after transplantation have been reported; however, the bleeding origin could not be determined. Our case is the only patient in which a gastrointestinal bleeding point, jejunal multiple angioectasia, was determined.
\end{abstract}

Key words: dyskeratosis congenita, portal hypertension, transplantation, hemorrhage

(Intern Med 55: 3441-3444, 2016)

(DOI: 10.2169/internalmedicine.55.7462)

\begin{abstract}
Introduction
Dyskeratosis congenita (DC) is a rare inherited disease characterized by the classical mucocutaneous triad of abnormal skin pigmentation, nail dystrophy, and leukoplakia in approximately $80-90 \%$ of patients $(1,2)$. Patients with DC are unable to maintain the telomere complex that protects the chromosome ends and consequently have very short telomeres (3). Shortened telomeres can cause a number of clinical conditions, such as bone marrow failure (BMF), pulmonary fibrosis, hepatic fibrosis, and a predisposition to malignancy (4). Patients with DC suffer premature morbidity, most commonly from BMF, which affects $80-90 \%$ of cases by the age of 30 years and is the leading cause of death (5). Bone marrow transplantation (BMT) is the only curative treatment for $\mathrm{BMF}$ in patients with $\mathrm{DC}$; however, some early and late unusual complications are occasionally observed (6). Gastrointestinal angioectasia in patients with DC is a rare complication that can cause life-threatening hemorrhage (7-9). This is the first report of small intestinal multiple angioectasia associated with portal hypertension in a pa-
\end{abstract}

tient with DC detected by balloon endoscopy.

\section{Case Report}

A 22-year-old woman was admitted to our hospital with recurrent melena and palpitation. She was diagnosed with DC and aplastic anemia, which was cured by BMT from an unrelated donor at 9 years old. In addition, she had undergone endoscopic variceal ligation for esophageal varices 2 months prior. Neither this disease nor any small intestinal diseases were found in her family history. The laboratory tests showed severe anemia (hemoglobin level $5.2 \mathrm{~g} / \mathrm{dL}$ ), a low platelet count $\left(123,000 \mathrm{~mm}^{3}\right)$, hypoalbuminemia $(1.9 \mathrm{~g} /$ $\mathrm{dL}$ ), and chronic renal dysfunction (creatinine level $2.47 \mathrm{mg} /$ dL). A blood coagulation disorder was not indicated.

A physical examination showed nail dystrophy, skin pigmentation, and leukoplakia, which are major clinical features of DC (Fig. 1). Abdominal ultrasonography revealed the retention of ascites and mild splenomegaly. Chest and abdominal computed tomography showed a mild interstitial shadow in the peripheral lung but no bleeding point. Upper endoscopy demonstrated multiple angioectasia with oozing from

${ }^{1}$ Department of Gastroenterology, Tokai University School of Medicine, Japan and ${ }^{2}$ Department of Cell Transplantation and Regenerative Medicine, Tokai University School of Medicine, Japan

Received for publication March 23, 2016; Accepted for publication April 18, 2016

Correspondence to Dr. Jin Imai, jin_sf_westportal@yahoo.co.jp 

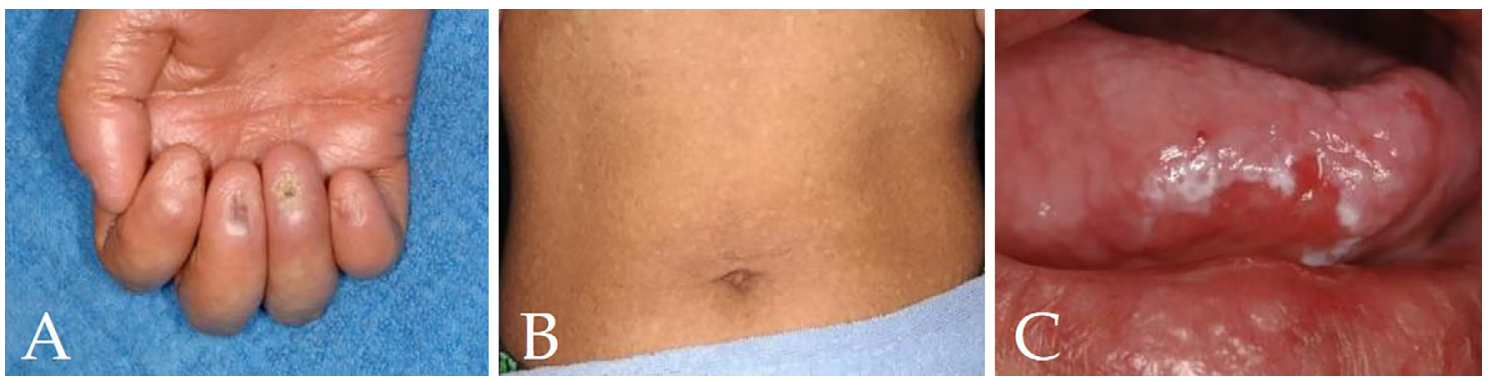

Figure 1. The major clinical features of dyskeratosis congenita. (A) Nail dystrophy, (B) skin pigmentation, and $(C)$ leukoplakia.

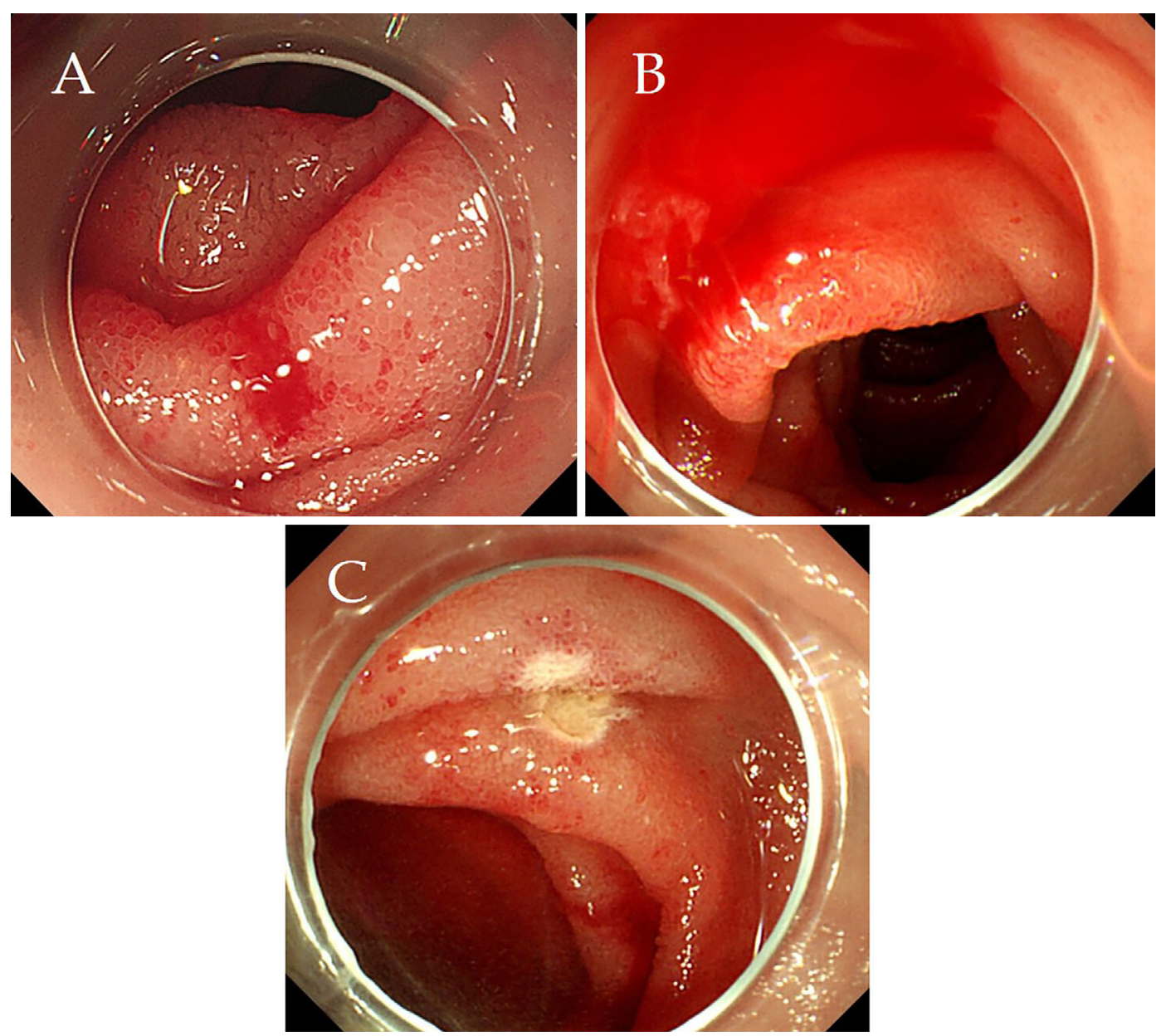

Figure 2. The upper endoscopy findings. (A) Multiple angioectasia with oozing in the second part of the duodenum. (B) Double balloon endoscopy showed mucosal edema, friability, hyperemia, and diffuse bleeding due to multiple angioectasia in the jejunum. (C) Argon plasma coagulation was used to treat the bleeding due to angioectasia.

the antrum and the second part of the duodenum (Fig. 2A). In addition, double balloon endoscopy demonstrated mucosal edema, friability, hyperemia, and diffuse bleeding from multiple angioectasia in the jejunum (Fig. 2B). Consequently, we performed as much argon plasma coagulation as possible (Fig. 2C). However, despite effective repeated balloon endoscopic hemostatic treatment, the oozing eventually became refractory to any treatment. After performing oral or anal double balloon endoscopy treatment 5 times, the patient died of uncontrollable bleeding after 27 days.

Discussion

We experienced a case of unrelated BMT for severe aplastic anemia associated with DC, where the patient died of uncontrollable refractory small intestinal bleeding. We noted three important findings with the present case.

First, this is the only case in which the gastrointestinal bleeding point, jejunal multiple angioectasia, was determined. Three previous cases of a fatal hemorrhage after 
Table. DC Patients of Fatal Intestinal Bleeding after Bone Marrow Transplantation (BMT).

\begin{tabular}{|c|c|c|c|c|c|c|c|c|}
\hline Patient & Sex & Age $(y r)$ at BMT & $\begin{array}{l}\text { History of intestinal bleeding } \\
\text { from BMT (period) }\end{array}$ & Endoscopic findings & $\begin{array}{l}\text { Location of } \\
\text { bleeding point }\end{array}$ & $\begin{array}{c}\text { Histrogical } \\
\text { opinon of } \\
\text { GVHD }\end{array}$ & outcome & Author \\
\hline 1 & M & 15 & 40 days & esophagitis, gastritis & no discription & No (capillitis) & death & Brazzola P, 2005...Ref.7 \\
\hline 2 & M & 11 & 12 months & erosive duodenitis & no discription & No & death & Amarasinghe $\mathrm{k}, 2007 \ldots$ Ref. 8 \\
\hline 3 & M & 21 & 21 days & $\begin{array}{l}\text { esopageal stenosis, diffuse } \\
\text { hemonhagic colitis }\end{array}$ & colon & No & lifesaving & Ehlert K, 2015...Ref.9 \\
\hline 4 & W & 9 & 13 years & jejunal multiple angioectagia & small intestine & No & death & Imai J, 2016. \\
\hline
\end{tabular}

BMT also underwent examination of the digestive tract by upper or lower endoscopy; however, a definitive bleeding point could not be determined. Amarasinghe et al. described a case of erosive duodenitis (8), and Brazzola et al. reported a case diagnosed with diffuse capillaritis of the brain and gut (7). The third patient demonstrated diffuse hemorrhagic colitis, but it was not described in detail (Table) (9). None of these previous cases had evidence of graft-versus-host disease on histological examinations. In our case, hemorrhagic gastrointestinal angioectasia was detected using double balloon endoscopy. We therefore recommend an examination of the small intestine in patients with DC with obscure gastrointestinal bleeding.

As for why these kinds of lesions appeared in our casefirst, angioectasia can be caused by portal hypertension. Hepatic involvement, including hepatomegaly, hemosiderosis, fibrosis, and cirrhosis have been reported in $10 \%$ of cases with DC (10). A possible association with non-cirrhotic portal hypertension has also been suggested, such as a jugular venous anomaly (11) or an unknown etiology (12). There is no definitive conclusion that can explain the appearance of hepatic complications in patients with DC; however, some studies have reported that loss-of-function telomerase gene variants are risk factors for sporadic cirrhosis (13). Our patient's medical history of esophageal varix and hypoalbuminemia and the finding of splenomegaly suggested that she suffered from liver cirrhosis with portal hypertension, but the cause was unknown. The prevalence of portal hypertensive changes in the small bowel varies widely across studies, reportedly as high as $82 \%$ in patients with cirrhosis, and some actively bleeding lesions can be seen in up to $17.8 \%$ of patients (14). Still, there have been few reports with data on small intestinal bleeding in patients with DC with cirrhosis.

Second, we suspected that the refractory jejunal intestinal bleeding occurred during the usual endoscopic treatment due to endothelial damage syndrome. BMT remains the only curative therapy for aplastic anemia associated with DC; however, endothelial damage or activation syndromes are common complications in these patients after transplantation (6). The clinical manifestations of endothelial syndromes affect many organs, including the liver, kidney, lung, and small bowel, each of which may manifest differently. The present case also had chronic renal dysfunction, chronic heart failure, several respiratory signs, and of course portal hypertension with jejunal multiple angioectasia. These conditions all share the common pathophysiology of vascular endothelial damage with platelet aggregation, and sometimes the coagulation system is activated as well (6). Notably, our patient could not be rescued, and among the previous three cases, only one case was a therapeutic success, although it remains unclear which part of the supportive therapy actually saved the patient in that particular case (9).

Third, the time to the onset of intestinal bleeding in our case $(+13$ years) differed substantially from that in the previous three cases $(+27$ days, +40 days, and +12 months after BMT; Table). Despite an improvement in the transplantation outcomes of many disorders, patients with DC still face significant challenges, specifically the 5-year posttransplantation survival probability, which is only $57 \%(15,16)$. Patients with DC who receive low-intensity conditioning have fewer early adverse events, but they continue to suffer from late severe outcomes, mainly pulmonary toxicity (16-19). Our facility also reported that a conditioning regimen containing low-dose irradiation and a minimum dose of fludarabine, cyclophosphamide, and anti-thymocyte globulin can enable the successful engraftment of alternative marrow in children with severe aplastic anemia and an excellent prognosis (20). Even though pulmonary toxicity, including fibrosis, which is mainly a late severe outcome, did not occur in our case, clinicians must be alert for this kind of unusual late complication after BMT for DC. Even if late severe complications such as pulmonary fibrosis are avoided, unusual late complications, including cirrhosis, in patients with DC after BMT can still be challenging to treat.

The authors state that they have no Conflict of Interest (COI).

\section{References}

1. Kirwan M, Dokal I. Dyskeratosis congenita, stem cells and telomeres. Biochim Biophys Acta 1792: 371-379, 2009.

2. Sakaguchi H, Nakanishi K, Kojima S. Inherited bone marrow failure syndromes in 2012. Int J Hematol 97: 20-29, 2013.

3. Mitchell JR, Wood E, Collins K. A telomerase component is defective in the human disease dyskeratosis congenita. Nature 402: 551-555, 1999.

4. Dokal I. Dyskeratosis congenita in all its forms. Br J Haematol 110: 768-779, 2000. 
5. Nelson ND, Bertuch AA. Dyskeratosis congenita as a disorder of telomere maintenance. Mutat Res 730: 43-51, 2012.

6. Rocha V, Devergie A, Socié G, et al. Unusual complications after bone marrow transplantation for dyskeratosis congenita. Br J Haematol 103: 243-248, 1998.

7. Brazzola P, Duval M, Fournet JC, et al. Fatal diffuse capillaritis after hematopoietic stem-cell transplantation for dyskeratosis congenita despite low-intensity conditioning regimen. Bone Marrow Transplant 36: 1103-1105, 2005.

8. Amarasinghe K, Dalley C, Dokal I, et al. Late death after unrelated-BMT for dyskeratosis congenita following conditioning with alemtuzumab, fludarabine and melphalan. Bone Marrow Transplant 40: 913-914, 2007.

9. Ehlert K, Rossig C, Groll AH, et al. Diffuse hemorrhagic colitis in a patient with dyskeratosis congenita after nonmyeloablative allogeneic hematopoietic stem cell transplantation. J Pediatr Hematol Oncol 37: e41-e44, 2015.

10. Brown KE, Kelly TE, Myers BM. Gastrointestinal involvement in a woman with dyskeratosis congenita. Dig Dis Sci 38: 181-184, 1993.

11. Yazgan Y, Demirtürk L, Ozel M, et al. A case of dyskeratosis congenita with portal hypertension associated with jugular venous anomaly. Turk J Gastroenterol 17: 66-69, 2006.

12. Redkar NN, Pandey DB, Jerajani HR, et al. Dyskeratosis congenita with portal hypertension of unknown etiology. J Assoc Physicians India 59: 260-263, 2011.

13. Fernández García MS, Teruya-Feldstein J. The diagnosis and treatment of dyskeratosis congenita: a review. J Blood Med 5: 157167, 2014.

14. Mekaroonkamol P, Cohen R, Chawla S. Portal hypertensive en- teropathy. World J Hepatol 7: 127-138, 2015.

15. Dietz AC, Orchard PJ, Baker KS, et al. Disease-specific hematopoietic cell transplantation: nonmyeloablative conditioning regimen for dyskeratosis congenita. Bone Marrow Transplant 46: 98104, 2011.

16. Gadalla SM, Sales-Bonfim C, Carreras J, et al. Outcomes of allogeneic hematopoietic cell transplantation in patients with dyskeratosis congenita. Biol Blood Marrow Transplant 19: 1238-1243, 2013.

17. Vuong LG, Hemmati PG, Neuburger S, et al. Reduced-intensity conditioning using fludarabine and antithymocyte globulin alone allows stable engraftment in a patient with dyskeratosis congenita. Acta Haematol 124: 200-203, 2010.

18. Nishio N, Takahashi $\mathrm{Y}$, Ohashi H, et al. Reduced-intensity conditioning for alternative donor hematopoietic stem cell transplantation in patients with dyskeratosis congenita. Pediatr Transplant 15: 161-166, 2011

19. Ayas M, Nassar A, Hamidieh AA, et al. Reduced intensity conditioning is effective for hematopoietic SCT in dyskeratosis congenita-related BM failure. Bone Marrow Transplant 48: 11681172, 2013.

20. Yabe M, Shimizu T, Morimoto T, et al. Alternative donor marrow transplantation in children with aplastic anemia using low-dose irradiation and fludarabine-based conditioning. Bone Marrow Transplant 46: 1148-1150, 2011.

The Internal Medicine is an Open Access article distributed under the Creative Commons Attribution-NonCommercial-NoDerivatives 4.0 International License. To view the details of this license, please visit (https://creativecommons.org/licenses/ by-nc-nd/4.0/).

(C) 2016 The Japanese Society of Internal Medicine http://www.naika.or.jp/imonline/index.html 